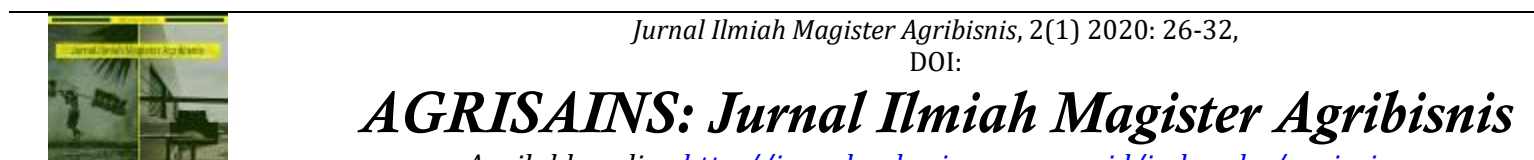

Available online http://iurnalmahasiswa.uma.ac.id/index.php/agrisains

\title{
Peningkatan Produksi Crude Palm Oil Melalui Kriteria Matang Panen Tandan Buah Segar untuk Optimalisasi Pendapatan Perusahaan
}

\section{Improving Crude Palm Oil Production Through Fresh Fruit Harvest Criteria for Optimization of Company Income}

\author{
Mastarida Lambok F Sitorus'), Erwin Nyak Akoeb'), Rasmulia Sembiring3), \\ Muhammad Akbar Siregar4) \\ 1) Program Studi Magister Agribisnis, Pascasarjana, Universitas Medan Area, Indonesia
}

2) Universitas Pancabudi, Indonesia

3) Fakultas Ekonomi, Universias Methodist Indonesia

4) Magister Agribisnis, Universitas Medan Area, Indonesia

\begin{abstract}
Abstrak
Penelitian ini bertujuan untuk mengetahui tingkat kematangan tandan buah segar (TBS) kelapa sawit yang masuk ke Pabrik Kelapa Sawit (PKS). Apabila tingkat kematangan TBS berubah (tidak standar) maka pendapatan perusahaan akan mengalami perubahan. Metode penelitian ini menggunakan pendekatan kuantitatif, jenis penelitiannya adalah pengumpulan data sekunder. Data diperoleh dari PKS Rambutan PTPN III dengan sampel kebun, yaitu Kebun Tanah Raja, Sei Putih, Sarang Giting, dan Rambutan. Data yang dikumpulkan adalah data sekunder berupa data series, yaitu produksi TBS, CPO, Inti dan Pendapatan tahun 2016 - 2018. Data dianalisis dengan menggunakan regresi linier berganda, optimasi dan uji beda dua rata-rata. Hasil penelitian menunjukkan komposisi buah panen berpengaruh sangat signifikan terhadap produksi CPO dan inti. Optimalisasi kematangan buah panen secara signifikan akan meningkatkan produksi minyak sawit dan inti sawit. Rata-rata produksi minyak sawit yang dapat dioptimalkan dari realisasi sesuai dengan kriteria kematangan buah adalah 4,734.16 ton atau 11,04\%. Rata-rata produksi inti sawit yang dapat dioptimalkan dari realisasi sesuai dengan kriteria kematangan buah adalah 1,091.31 ton atau $11,54 \%$. Optimalisasi kematangan buah panen secara signifikan akan meningkatkan pendapatan dari minyak sawit dan inti sawit. Rata-rata pendapatan yang dapat dioptimalkan dari optimalisasi produksi minyak sawit adalah Rp. 38,862.51 juta atau $11,14 \%$. Rata-rata pendapatan yang dapat dioptimalkan dari optimalisasi produksi Inti Sawit adalah Rp. $7,350.05$ juta atau $11,57 \%$
\end{abstract}

Kata kunci: kematangan buah, optimalisasi, produksi, pendapatan

\section{Abstract}

This study aims to determine the maturity level of oil palm fresh fruit bunches (FFB) that enter the Palm Oil Mill (POM). If the maturity level of FFB changes (not standardized), the company's income will change. This research method uses a quantitative approach, the type of research is secondary data collection. Data were obtained from POM of Rambutan PTPN III with garden samples, namely the Raja Tanah Gardens, Sei Putih, Sarang Giting, and Rambutan. The data collected is secondary data in the form of data series, namely FFB production, CPO, Core and Revenue in 2016 - 2018. Data were analyzed using multiple linear regression, optimization and two different test averages. The results showed that the composition of harvested fruit had a very significant effect on CPO and core production. Optimizing the maturity of the fruit harvest will significantly increase the production of palm oil and palm kernel. The average palm oil production that can be optimized from the realization in accordance with the fruit maturity criteria is 4,734.16 tons or 11.04\%. The average palm kernel production that can be optimized from the realization in accordance with the fruit maturity criteria is 1,091.31 tons or $11.54 \%$. Optimizing the maturity of harvested fruit will significantly increase revenues from palm oil and palm kernel. The average income that can be optimized from optimizing palm oil production is Rp. 38,862.51 million or $11.14 \%$. The average income that can be optimized from optimizing the production of Palm Oil is Rp. 7,350.05 million or 11.57\% Keywords: fruit maturity, optimization, production, income

How to Cite: Sitorus, M. L.F., E. N. Akoeb, R. Sembiring \& M. A. Siregar. (2020). Peningkatan Produksi Crude Palm Oil Melalui Kriteria Matang Panen Tandan Buah Segar. Jurnal Ilmiah Magister Agribisnis, 2(1) 2020: 2632,

*E-mail: erwinnyak@yahoo.com ISSN 2550-1305 (Online)

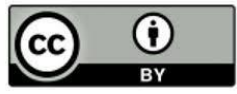




\section{PENDAHULUAN}

Komoditas kelapa sawit merupakan salah satu komoditas yang penting di Indonesia, terlebih sebagai Negara pengekspor minyak kelapa sawit tertinggi didunia yang mencapai 31.1 juta ton pada tahun 2016 dan menyumbang devisa rata-rata 15 miliar dollar AS per tahun.

Data sampai dengan Desember 2016, secara kumulatif neraca perdagangan tanpa sawit mencatat defisit 9,18 miliar dollar AS, akan tetapi dapat ditutupi dengan ekspor minyak sawit secara kumulatif mencapai 17,8 miliar dollar AS, sehingga akhir tahun 2016 neraca perdagangan secara kumulatif mencatat surplus 8,62 miliar dollar AS. Hal ini mencerminkan betapa perkebunan kelapa sawit merupakan salah satu pondasi yang kuat bagi tumbuh dan berkembangnya sistem agribisnis Indonesia. Sistem agribisnis kelapa sawit yang merupakan gabungan subsistem sarana produksi pertanian (agroindustri hulu), industri hilir, dan pemasaran.

Indonesia membutuhkan sarana industri yang dapat meningkatkan pembangunan perekonomian dan jelas bahwa industri kelapa sawit adalah salah satunya. Hal ini dikarenakan kelapa sawit merupakan sumber daya alam yang dapat diperbarui, dan Indonesia memiliki sumber daya yang mendukung industri kelapa sawit berupa lahan yang subur, sinar matahari yang melimpah sepanjang tahun, iklim yang sesuai dan tenaga kerja yang produktif.

Negara Indonesia terdiri dari 17.504 pulau, dengan luas daratan Indonesia adalah 1.922.570 kM-2 dan luas perairannya 3.257.483 kM-2. Sumber daya alam Indonesia mempunyai tanah pertanian sebesar $10 \%$, perkebunan sebesar $7 \%$, padang rumput sebesar 7\%, hutan dan daerah berhutan sebesar 62\% dan lainnya sebesar $14 \%$.

Luas lahan perkebunan sawit Indonesia pada tahun 2016 mencapai 11,91 juta Ha dan untuk tahun 2017 diperkirakan akan meningkat sebesar 3,3\% menjadi 12,3 juta Ha, yang terdiri dari 4,76 juta Ha perkebunan rakyat, 6,8 juta Ha perkebunan swasta dan perkebunan Negara 753 ribu Ha. Dalam 10 tahun terakhir, rata-rata peningkatan luas lahan perkebunan kelapa sawit mencapai 5,90\% dimana pada tahun 2011 merupakan peningkatan tertinggi yaitu dari 7,24 juta Ha menjadi 8,99 juta Ha.

Produktivitas minyak sawit untuk Perkebunan Rakyat hanya mencapai 3.147 kg/Ha, untuk Perkebunan Besar Negara $3.802 \mathrm{Kg} / \mathrm{Ha}$, serta Perkebunan Besar Swasta sebesar $3.948 \mathrm{Kg} / \mathrm{Ha}$. Sementara ekspor minyak sawit pada 2015 naik 15,6 persen menjadi 26,47 juta ton dari tahun sebelumnya.

Proyeksi kebutuhan minyak nabati dunia pada tahun 2020 menjadi topik yang sangat menarik dibahas apalagi dengan pertambahan penduduk dengan potensi populasi naik menjadi 7,72 miliar jiwa di tahun 2020 yang sebelumnya berjumlah 6,92 miliar ditahun 2010 maka kebutuhan minyak nabati pastilah semakin meningkat. Pada 2020, jumlah produksi minyak sawit atau CPO sebesar 78 juta ton. Disusul dengan minyak kedelai berjumlah 53,2 juta, minyak bunga matahari sebesar 18,3 juta ton dan minyak kanola 31,5 juta ton. Sisanya berasal dari 13 jenis minyak lain yang berjumlah 55 juta ton seperti minyak inti sawit, minyak kelapa, minyak kacang tanah, dan minyak zaitun sesuai dengan presentasi Thomas Mielke, Analis Oilworld, yang berjudul "The Oil World Supply and demand Forecast for the Year 2020" 
Salah satu cara dalam mengoptimalkan pengelolaan agribisnis adalah optimalisasi produksi mulai dari optimalisasi potensi produksi TBS hingga optimalisasi potensi produksi CPO. Dengan mengoptimalkan hasil produksi untuk meningkatkan pendapatan yang akhirnya akan meningkatkan cash flow dan profit perusahaan. Oleh karena itu tujuan penelitian ini yaitu untuk menganalisis optimalisasi produksi Crude Palm Oil (CPO) dan Inti Sawit (Palm Kernel) sesuai kematangan panen TBS, menganalisis produksi Crude Palm Oil (CPO) dan Inti Sawit (Palm Kernel) apabila faktor kematangan buah yang di panen berubah, dan menganalisis pendapatan perusahaan apabila produksi Crude Palm Oil (CPO) dan Inti Sawit (Palm Kernel) yang diperoleh perusahaan apabila kematangan buah yang di panen berubah.

\section{METODE PENELITIAN}

Metode yang digunakan dalam penelitan ini adalah metode studi kasus dengan lokasi di PT. Perkebunan Nusantara III (Persero) PKS Kebun Rambutan. Metode studi kasus adalah penelitian terhadap suatu kasus khusus secara intensif dan mendalam terhadap objek tertentu. Sampel dalam penelitian ini adalah pada sortasi, laboratorium dan pengolahan. Data yang digunakan dalam penelitian ini terdiri dari data primer dan data sekunder. Data primer diperoleh dari data masa lalu yang tersedia dan diamati di PT. Perkebunan Nusantara III (Persero) PKS Kebun Rambutan yaitu perubah data tiga tahun terakhir disetiap bulannya sedangkan untuk data sekunder diperoleh dari Instansi terkait yaitu Badan Pusat Statistik, GAPKI, Dinas Perkebunan dan literature-literatur yang terkait dengan penelitian.

Data primer yang diperoleh dari dari penelitian akan menunjukkan angka-angka rendemen potensi untuk setiap tahun tanam pada masing-masing kebun yang diteliti yaitu Kebun Rambutan, Kebun Tanah Raja, Kebun Sarang Giting dan Kebun Sei Putih. Hasil rendemen potensi akan dikurang terhadap standard kehilangan (losis) yang diizinkan untuk setiap produk yang dihasilkan (minyak sawit dan inti sawit). Analisis yang digunakan yaitu analisis regresi untuk mengetahui pengaruh kematangan buah terhadap produksi minyak kelapa sawit.

Optimalisasi produksi dapat dihitung dengan membandingkan realisasi produksi yang diperoleh dengan potensi produksi yang akan diperoleh jika dilaksanakan penghitungan rendemen potensi dikali dengan jumlah TBS realisasi yang diolah.

Potensi Optimalisasi Produksi $(\mathrm{Kg})=\mathrm{C}-\mathrm{D}$

Keterangan :

C : Hasil Olah Realisasi Produksi Minyak/ Inti Sawit (Kg)

D : Potensi Hasil Olah Produksi Minyak/ Inti Sawit (Kg)

Optimalisasi pendapatan dapat dihitung dengan membandingkan realisasi produksi yang diperoleh dikali harga rata-rata produksi minyak atau inti sawit pada bulan berjalan $(\mathrm{Rp} / \mathrm{Kg})$ dengan potensi produksi yang akan diperoleh jika dilaksanakan penghitungan rendemen potensi dikali dengan jumlah TBS realisasi yang diolah dikali harga rata-rata produksi minyak atau inti sawit pada bulan berjalan $(\mathrm{Rp} / \mathrm{Kg})$. Potensi Optimalisasi Pendapatan $(\mathrm{Rp})=(\mathrm{C} \times \mathrm{E})-(\mathrm{D} \times \mathrm{E})$ 
Keterangan :

C : Hasil Olah Realisasi Produksi Minyak/ Inti Sawit (Kg)

D : Potensi Hasil Olah Produksi Minyak/ Inti Sawit (Kg)

E : Harga Produksi Minyak/ Inti Sawit (Rp/Kg)

\section{HASIL DAN PEMBAHASAN}

\section{Produksi Minyak Sawit dan Inti}

Berdasarkan tabel 1 nilai koefisien regresi (B), diketahui bahwa variabel buah busuk berpengaruh negatif dan signifikan terhadap produksi CPO. Artinya bahwa semakin banyak buah busuk, maka produksi CPO akan berkurang secara signifikan. Selanjutnya seluruh kelas buah yang lain, yaitu: mentah, matang-1, matang-2, matang-3 dan matang-4, berpengaruh positif terhadap produksi CPO, tetapi buah matang-1 berpengaruh tidak signifikan (nilai signifikansi $>0.05$ ). Berdasarkan kematangan buah, dapat dilihat bahwa buah matang-3 paling besar dan signifikan pengaruhnya terhadap produksi CPO.

Dengan demikian, upaya yang dapat dilakukan untuk meningkatkan produksi CPO adalah dengan meniadakan buah busuk, kemudian mengurangi buah mentah, serta meningkatkan kematangan buah hingga matang-3.

Tabel 1. Pengaruh Tingkat Kematangan Buah terhadap Produksi Minyak Kelapa Sawit (CPO)

\begin{tabular}{|c|c|c|c|c|c|c|}
\hline \multicolumn{7}{|c|}{ Coefficients $^{a}$} \\
\hline & \multirow[t]{2}{*}{ Model } & \multicolumn{2}{|c|}{ Unstandardized Coefficients } & \multirow{2}{*}{$\begin{array}{c}\begin{array}{c}\text { Standardized } \\
\text { Coefficients }\end{array} \\
\text { Beta } \\
\end{array}$} & \multirow[t]{2}{*}{$\mathrm{t}$} & \multirow[t]{2}{*}{ Sig. } \\
\hline & & $\mathrm{B}$ & Std. Error & & & \\
\hline \multirow[t]{7}{*}{1} & (Constant) & 34.641 & 15.056 & & 2.301 & .039 \\
\hline & Mentah & .484 & .225 & .019 & 2.153 & .051 \\
\hline & Matang1 & .248 & .014 & .517 & 17.766 & .000 \\
\hline & Matang2 & .142 & .032 & .180 & 4.415 & .001 \\
\hline & Matang3 & .272 & .010 & .506 & 26.942 & .000 \\
\hline & Matang4 & .170 & .012 & .132 & 13.690 & .000 \\
\hline & Busuk & -1.269 & .527 & -.021 & -2.410 & .032 \\
\hline
\end{tabular}

Sumber: Data Sekunder (diolah), 2018

Berdasarkan tabel 2 nilai koefisien regresi (B), diketahui bahwa semua kelas buah berpengaruh positif terhadap produksi minyak inti, tetapi buah mentah dan buah busuk berpengaruh tidak signifikan. Artinya bahwa semakin banyak buah mentah dan busuk tidak secara nyata mempengaruhi jumlah minyak inti. Selanjutnya seluruh kelas buah yang lain, yaitu: matang-1, matang-2, matang-3 dan matang-4, berpengaruh signifikan terhadap produksi minyak inti. Berdasarkan kematangan buah, dapat dilihat bahwa buah matang-2 dan matang-3 paling besar dan signifikan pengaruhnya terhadap produksi minyak inti.

Dengan demikian, upaya yang dapat dilakukan untuk meningkatkan produksi minyak inti adalah dengan mengurangi buah mentah dan buah busuk, serta meningkatkan kematangan buah hingga matang-3 dan matang-2. 
Sitorus, M. L.F., E. N. Akoeb, R. Sembiring \& M. A. Siregar. Peningkatan Produksi Crude Palm Oil Melalui Kriteria Matang Panen Tandan Buah Segar

Tabel 2. Pengaruh Tingkat Kematangan Buah terhadap Produksi Minyak Inti

\begin{tabular}{|c|c|c|c|c|c|c|}
\hline \multicolumn{7}{|c|}{ Coefficients $^{\mathrm{a}}$} \\
\hline \multirow{9}{*}{1} & \multirow{9}{*}{$\begin{array}{l}\text { Model } \\
\text { (Constant) } \\
\text { Mentah } \\
\text { Matang1 } \\
\text { Matang2 } \\
\text { Matang3 } \\
\text { Matang4 } \\
\text { Busuk }\end{array}$} & \multirow{2}{*}{\multicolumn{2}{|c|}{$\begin{array}{l}\text { Unstandardized Coefficients } \\
\begin{array}{cc}\text { B } & \text { Std. Error }\end{array}\end{array}$}} & \multirow{2}{*}{$\begin{array}{c}\text { Standardized } \\
\text { Coefficients } \\
\text { Beta }\end{array}$} & \multirow[b]{2}{*}{$\mathrm{t}$} & \multirow[b]{2}{*}{ Sig. } \\
\hline & & & & & & \\
\hline & & 1.267 & 10.684 & & .119 & .907 \\
\hline & & .130 & .159 & .023 & .818 & .428 \\
\hline & & .025 & .010 & .237 & 2.535 & .025 \\
\hline & & 091 & .023 & .520 & 3.981 & .002 \\
\hline & & .039 & .007 & .324 & 5.383 & .000 \\
\hline & & .030 & .009 & .106 & 3.433 & .004 \\
\hline & & .227 & .374 & .017 & .608 & .554 \\
\hline \multicolumn{7}{|c|}{ a. Dependent Variable: INTI } \\
\hline
\end{tabular}

Sumber: Data Sekunder (diolah), 2018

Berdasarkan hasil analisis diperoleh bahwa kematangan buah berpengaruh signifikan terhadap produksi minyak sawit dan inti dapat dilihat pada tabel 1 dan 2 . Hal ini berarti bahwa komposisi buah yang dipanen dan diolah masih dapat dioptimalkan sehingga diperoleh minyak sawit dan inti secara maksimal. Dengan demikian bahwa produksi Crude Palm Oil (CPO) dan Inti Sawit (Palm Kernel) yang diperoleh perusahaan selama ini belum optimal. Belum optimalnya produksi minyak sawit dapat diketahui dari adanya kelas buah yang berpengaruh negatif terhadap produksi minyak sawit, yaitu buah busuk. Berdasarkan hasil analisis, buah busuk yang terikut dipanen dan diolah di pabrik secara signifikan berpengaruh negatif terhadap produksi minyak sawit, artinya secara signifikan mengurangi produksi minyak sawit. Selain itu, buah mentah menunjukkan pengaruh positif terhadap produksi minyak sawit, tetapi tidak signifikan.

Sehubungan dengan hal tersebut maka dilakukan optimalisasi komposisi kematangan buah yang sekaligus juga akan mempengaruhi rendemen minyak sawit dan inti di dalam buah. Dalam optimalisasi, yang pertama sekali dilakukan adalah dengan meniadakan buah busuk dan buah mentah, kemudian mengatur komposisi kematangan buah, yaitu matang-1, matang-2, matang-3, dan matang-4 sehingga diperoleh rendemen yang maksimal. Realisasi di kebun saat ini, komposisi kematangan buah adalah matang-1, matang-2, dan matang-3 dengan komposisi rata-rata masing-masing 28-30\%, selanjutnya matang-4 dengan komposisi rata-rata 9-10\%, sisanya buah mentah dan busuk. Dalam optimalisasi dilakukan pengaturan komposisi kematangan buah, yaitu: matang-1 5\%, matang-2 15\%, matang-3 dan matang-4 masing-masing 40\%. Dengan demikian seluruh buah yang dipanen dan diolah adalah yang sudah termasuk dalam kategori matang. Dengan dipenuhi komposisi kematangan buah tersebut, maka rendemen minyak dan inti yang diperoleh juga menjadi maksimal.

\section{Peningkatan Produksi dan Pendapatan}

Optimalisasi komposisi kematang buah bertujuan untuk meningkatan produksi minyak kelapa sawit dan inti, yang kemudian secara langsung juga akan mempengaruhi pendapatan perusahaan. Perbedaan produksi dan pendapatan minyak kelapa sawit dan inti pada kondisi realisasi dan optimalisasi disajikan sebagai berikut. 
Tabel 3. Produksi dan Pendapatan Real dan Optimalisasi

\begin{tabular}{c|r|r|r|r|r|r|}
\hline \multirow{2}{*}{ Uraian } & \multicolumn{2}{|c|}{ Produksi (ton) } & \multicolumn{2}{c|}{ Pendapatan (Rp Juta) } & \multicolumn{2}{c}{ Peningkatan (\%) } \\
\cline { 2 - 7 } & \multicolumn{1}{|c|}{ Realisasi } & Optimalisasi & \multicolumn{1}{c}{ Realisasi } & \multicolumn{1}{c}{ Optimalisasi } & \multicolumn{1}{c}{ Produksi } & Pendapatan \\
\hline Minyak Sawit & $42,868.921$ & $47,603.081$ & $348,720.280$ & $387,582.789$ & 11,04 & 11,14 \\
\hline Inti Sawit & $9,456.735$ & $10,548.049$ & $63,543.197$ & $70,893.249$ & 11,54 & 11,57 \\
\hline
\end{tabular}

Sumber: Data Sekunder (diolah), 2018

Dari hasil data tabel di atas, dapat dilihat sebagai berikut :

1. Rata-rata produksi minyak sawit yang dapat dioptimalkan dari realisasi sesuai dengan kriteria kematangan buah adalah 4,734.16 ton atau 11,04\%,

2. Rata-rata pendapatan yang dapat dioptimalkan dari optimalisasi produksi minyak sawit adalah Rp. 38,862.51 juta atau 11,14\%,

3. Rata-rata produksi inti sawit yang dapat dioptimalkan dari realisasi sesuai dengan kriteria kematangan buah adalah 1,091.31 ton atau 11,54\%,

4. Rata-rata pendapatan yang dapat dioptimalkan dari optimalisasi produksi Inti Sawit adalah Rp. 7,350.05 juta atau 11,57\%.

Berdasarkan hasil analisis bahwa terdapat perbedaan produksi minyak sawit dan inti sawit yang signifikan antara realisasi dan kondisi optimalisasi. Dengan demikian, bahwa dengan optimalisasi kematangan buah panen, maka secara signifikan akan meningkatkan produksi minyak sawit dan inti sawit. Hasil analisis juga menunjukkan bahwa terdapat perbedaan pendapatan dari minyak sawit dan inti sawit yang signifikan antara realisasi dan kondisi optimalisasi. Dengan demikian, bahwa dengan optimalisasi kematangan buah panen, maka secara signifikan akan meningkatkan pendapatan dari minyak sawit dan inti sawit.

\section{SIMPULAN}

Optimalisasi kematangan buah panen secara signifikan akan meningkatkan produksi minyak sawit dan inti sawit. Optimalisasi kematangan buah panen secara signifikan akan meningkatkan pendapatan dari minyak sawit dan inti sawit. Kedepannya diharapkan Perusahaan PT. Perkebunan Nusantara III (Persero) agar tetap memastikan terlaksananya panen sesuai dengan kriteria matang panen yang telah ditentukan upaya optimalisasi produksi dan pendapatan dari hasil jual produksi yang meningkat. Manajemen Kebun dan PKS agar terus menerus berkoordinasi perihal pentingnya pelaksanaan konsistensi pelaksanaan panen sesuai dengan kriteria matang panen dan agar dapat secara konsisten mensosialisasikan pentingnya displin dan kepedulian dalam pelaksanaan panen upaya pencapaian target produksi yang lebih tinggi.

\section{DAFTAR PUSTAKA}

Abdullah, A. (2005). Prinsip Penilaian sensori. Terjemahan Nurul Huda. Penerbit UNRI Press Pekan Baru, Pekan Baru.

Alsa, A. (2004). Pendekatan Kuantitatif \& Kualitatif Serta Kombinasinya dalam Penelitian Psikologi. Pustaka Pelajar, Yogyakarta.

Abduljabar, Bambang, \& Darajat, Jajat. (2013). Aplikasi Statistika dalam Penjas. Universitas Pendidikan Indonesia, Bandung.

Ayustaningwarno, Fitriyono. (2012). Proses Pengolahan Dan Aplikasi Minyak Sawit Merah Pada Industri Pangan. Vitasphere, ISSN: 2085-7683, vol. II, p.1-11.

Elwood S. Buffa, Rakesh K. Sarin. John Wiley \& Sons. (1987). Modern production operations management.

Fauzi, Y. (2008). Kelapa Sawit : Budi Daya, Pemanfaatan Hasil dan Limbah, Analisis Usaha dan Pemasaran. Cetakan 24. Penebar Swadaya, Jakarta.

Fauzi, Y. (2012). Kelapa Sawit Budidaya, Pemanfaatan Hasil dan Limbah, Analisis dan Pemasaran. Penebar Swadaya, Jakarta. 
Sitorus, M. L.F., E. N. Akoeb, R. Sembiring \& M. A. Siregar. Peningkatan Produksi Crude Palm Oil Melalui Kriteria Matang Panen Tandan Buah Segar

Fathurrahman. (2013). Perbandingan Komposisi Asam Lemak Kelapa Sawit (Elaeis Guineensis Jacq.) Hasil Transformasi Genetik. Jurnal Agroekoteknologi, vol. 3, No. 2, p.11-20.

Gay, L.R. (1982). Educational Research Competencies for Analsis \& Application 2nd Edition. A Bell \& Howell Company, Ohio.

Hadi, Sutrisno. (1985). Metodologi Research. Yogyakarta: Yasbit, Fak. Psikologi UGM.

Mangoensoekarjo, S \& H. Semangun. (2003). Manajemen Agrobisnis Kelapa Sawit. Gajah Mada University Press, Yogyakarta.

Pahan, I. (2008). Panduan Lengkap Kelapa Sawit. Penebar Swadaya. Jakarta.

Ponten M. Naibaho. (1998). Teknik Pengolahan Kelapa Sawit. Penerbit Pusat Penelitian Kelapa Sawit.

Setyamidjaja, D. (2006). Kelapa Sawit. Kanisius, Yogyakarta. 